\title{
A carta en galego de Magdalena García de Ogando a Martín Sarmiento. Edición interpretativa e breve comentario lingüístico
}

\author{
The letter in Galician language from Magdalena Garcia de \\ Ogando to Martín Sarmiento. Interpretative edition \\ and brief linguistic comment
}

\author{
Ramón Mariño Paz \\ Universidade de Santiago de Compostela \\ Departamento de Filoloxía Galega \\ ramon.marino.paz@usc.es
}

[recibido 29/01/2014, aceptado 14/04/2014]

\section{RESUMO}

Ofrécense neste artigo unha reprodución fotográfica e unha edición interpretativa da carta en lingua galega que Magdalena García de Ogando lle escribiu a Martín Sarmiento probablemente non moito despois de outubro de 1755. A edición acompáñase dunha sumaria análise lingüística do texto.

PALABRAS CHAVE: galego medio, carta en galego, edición e estudo.

Mariño PAZ, R. (2014): "A carta en galego de Magdalena García de Ogando a Martín Sarmiento. Edición interpretativa e breve comentario lingüístico", Madrygal (Madr.), 17: 67-79.

\section{RESUMEN}

En este artículo se ofrecen una reproducción fotográfica y una edición interpretativa de la carta en lengua gallega que Magdalena García de Ogando le escribió a Martín Sarmiento probablemente no mucho después de octubre de 1755. La edición se acompaña de un sumario análisis lingüístico del texto.

PALABRAS CLAVE: gallego medio, carta en gallego, edición y estudio.

Mariño PAz, R. (2014): "La carta en gallego de Magdalena García de Ogando a Martín Sarmiento. Edición interpretativa y breve comentario lingüístico", Madrygal (Madr.), 17: 67-79.

\section{ABSTRACT}

A photographic reproduction and an interpretative edition of the letter in Galician language that Magdalena García de Ogando wrote to Martín Sarmiento, probably not long after October 1755, are presented in this article. Besides, a brief linguistic analysis of the text is carried out.

KEY WORDS: Middle Galician, letter in Galician, edition and analysis.

Mariño PaZ, R. (2014): “The letter in Galician language from Magdalena García de Ogando to Martin Sarmiento. Interpretative edition and brief linguistic comment", Madrygal (Madr.), 17: 67-79.

SUMARIO: 1. Localización e datación do manuscrito. 2. Edición interpretativa. 2.1. Notas de edición. 3. Comentario lingüístico. 4. Referencias bibliográficas. 
1. LOCALIZACIÓN E DATACIÓN DO MANUSCRITO

A carta de Magdalena García de Ogando que neste artigo edito e comento está contida entre os folios $202 \mathrm{r}$ e $203 \mathrm{v}$ do segundo ${ }^{1}$ dos dous volumes de correspondencia dirixida a Martín Sarmiento que o padre Sobreira reuniu e entregou o 29 de decembro de 1786 á Real Academia da Historia (RAH), onde hoxe seguen depositados co título de Cartas originales escritas al $P$. Fr. Martín Sarmiento (1733-71) de personajes y literatos (signaturas 9-5761 e 5762). María Magdalena García de Ogando era cuñada do padre Sarmiento, xa que casara co seu irmán Francisco Xavier, con quen o erudito frade bieito mantivo unha copiosa correspondencia. Mais Magdalena, residente en Pontevedra pero criada en Viveiro, foi para Sarmiento, ademais de cuñada, rica fonte de información sobre voces usadas na vila do Landro e na súa rodeada: "Siempre que hablo de Vivero -anotou en 1745-, no es porque yo haya estado allí, sino porque la mujer de mi hermano Francisco Xavier se había criado en Vivero y a ella oí muchas voces que allí se usan" (Sarmiento 1973: 280).

A peza de dona Magdalena está precedida dunha carta en castelán da mesma remitente que se encontra entre os folios 200r e 201v. Estas misivas, as dúas sen data, son as que abren a sección de "Cartas de Señoras Mugeres" e van seguidas dunha de Isabel Fernández de Murga do 15 de agosto de 1767 e doutra anónima do 26 de marzo de 1768. Dado o criterio cronolóxico que Sobreira adoptou para ordenar as cartas, é obvio que el supuxo que as de Magdalena García de Ogando se escribiran antes do 15 de agosto de 1767.

Para unha máis precisa aproximación á datación do texto que edito deita luz tamén a seguinte pasaxe da carta en castelán: "i si no dijanlo los pobres quando $\mathrm{Vm}$. estaba aca, que les daba a tres i quatro quartos i preguntaba si abia mas" (201r.). ¿Estarase a referir aquí a remitente á estadía de Sarmiento en Pontevedra que rematou en novembro de 1745 ou á que finalizou en outubro de 1755? O arco cronolóxico que cobren as cartas do volume segundo que si están datadas, declarado na nota 1 deste artigo, invita a pensar que Magdalena estaría a falar na carta en castelán da viaxe de entre 1754 e 1755, suposición que do meu punto de vista cadra coa sensación de que a súa filla Farruquiña xa non era unha nena cando ela lle enviou ao cuñado a comunicación en galego que aquí edito, pois un rosario de Xerusalén ao uso da corte non parece que puidese ser un regalo espontaneamente querido e pedido por unha rapaza (liñas 23-26). E, a meu ver, todo isto cadra tamén co feito de que o 1 de maio de 1754 Farruquiña xa tivese un fillo (Sarmiento 1995: 481). Por todo isto, coido que as dúas cartas de dona Magdalena que Sobreira reuniu deberon de ser escritas non moito despois de outubro de 1755.

A misiva en galego que abordo neste artigo xa mereceu a atención de Rodríguez Montederramo (1998), quen a deu a coñecer como novo testemuño da fidelidade do beneditino pontevedrés á causa da lingua galega. $\mathrm{O}$ que con este meu traballo me propoño facer é corrixir algúns erros de edición que a meu ver cometeu Rodríguez Montederramo na súa contribución e someter o texto a un exame lingüístico que, por breve que sexa, poida situalo acaidamente no contexto do desenvolvemento histórico do galego medio, tanto no tocante aos seus aspectos sociais como no relativo aos usos gráficos e ás mudanzas fonéticas, fonolóxicas, gramaticais e lexicais que por aqueles tempos estaba a experimentar.

\footnotetext{
${ }^{1}$ Na realidade, no arquivo da Real Academia da Historia este volume aparece como o primeiro (9-5761) dos dous que Sobreira confeccionou con correspondencia enviada a Sarmiento. Ora ben, a meu parecer, o primeiro dos dous volumes é verdadeiramente o que porta a signatura 9-5762, xa que, ademais de ser o que se abre co prólogo explicativo de Sobreira, é tamén o que contén as cartas dos remitentes que lle escribiron a súa primeira misiva a Sarmiento entre o 28 de maio de 1733 e o 20 de decembro de 1747, ao paso que o volume 9-5761 reúne pezas dos remitentes que se dirixiron por primeira vez a frei Martín entre o 19 de xuño de 1748 e o 12 de agosto de 1771.
} 


\section{EDICIÓN INTERPRETATIVA}

Xunto á reprodución fotográfica do manuscrito, achego tamén a súa imprescindible edición interpretativa. A que aquí ofrezo é unha edición que pretende poñer á disposición do interesado un texto apto para o estudo grafofonolóxico, fonético, morfolóxico, sintáctico e lexical, sen por iso renunciar a configurarse como un produto lexible para un lector medio non especialista nin en cuestións filolóxicas nin en cuestións paleográficas. En atención a isto, tomei as decisións que deseguido detallo.

Non modifiquei os usos gráficos do manuscrito, coa única excepción do relativo ao emprego de maiúsculas e minúsculas, que alterei quer para introducir a maiúscula como letra inicial de diversos nomes de lugar e de persoa que no manuscrito non a levan, quer como letra inicial de palabras que aparecen despois dun punto introducido por min no desempeño da tarefa editorial.

Non intervín en ningún caso sobre a acentuación. Respecto disto, cómpre advertir que no manuscrito a letra $<\mathrm{i}>$ leva sobrescrita unha plica orientada á dereita que eu entendo como trazo constitutivo dela, e non como til agudo. Por esta razón, transcribina sempre como $<\mathrm{i}>$, sen ningún trazo engadido.

A carta está escasa e deficientemente puntuada, polo que me pareceu que, para facilitar a súa lectura, debía intervir a fondo neste aspecto. É obvio que con esta operación introducín a miña interpretación persoal do texto, que, atinada ou non, pode en todo caso ser avaliada polos lectores deste artigo mediante as oportunas comprobacións na reprodución fotográfica que ofrezo nas últimas páxinas.

Descompuxen en parágrafos a redacción do manuscrito, que se presenta, ao igual ca a carta en castelán que o precede, como un texto un pouco atrapallado, sen puntos á parte e con escaso uso dos outros sinais de puntuación. A meu ver, esta operación tamén fai máis doada a lectura da carta, xa que agrupa en parágrafos diferentes os diversos contidos que nela se reuniron.

No manuscrito a letra está moi apertada e apenas hai separación entre as palabras. Eu regularicei esta separación, coa excepción dos pronomes enclíticos, que mantiven separados das formas verbais de que dependen cando así están no texto: decir lle (1. 3).

Inserín entre corchetes as letras omitidas no manuscrito por evidente lapso involuntario $(d[e], 1.7 ; m[u] i, 1.18 ; u[n], 1.21)$, así como as miñas correccións de erros debidos ao que estimo simple descoido da remitente (faruquina $>$ Faruqui[ñ]a, 1. 15).

Os desenvolvementos de abreviaturas púxenos en letra itálica e sen corchetes.

Inserín entre ángulos as letras que, sobrescritas ou infraescritas, foron engadidas pola propia redactora da carta para arranxar o texto no transcurso dunha probable relectura.

Indico entre parénteses o inicio de cada un dos catro folios e marco cunha pleca ( $\mid$ ) as transicións entre liñas.

En notas de rodapé ofrezo brevísima información sobre varios nomes de persoa e de lugar mencionados na carta. Despois da edición interpretativa presento como "Notas de edición" distintas observacións a respecto dalgunhas particularidades do manuscrito, das decisións editoriais tomadas por min e dalgúns aspectos da edición de Rodríguez Montederramo (1998: 463). Nesta, coma na miña, fíxose intervención sobre a acentuación, a puntuación, a segmentación do texto en parágrafos e a unión e separación de palabras, mais non se practicou o desenvolvemento das abreviaturas.

\section{(f. 202r) Meu irmanciño:}

Ai moi|tos coreos que non lle escri|bin por nono abougar | con tantas cartas. Agora $\mid$ non podo mais esperar | sin escribir duas letri|ñas para decir lle que es|tou boa, e Faruquiña ${ }^{2}$ e ma|is toda a parentela. Jabi|er ${ }^{3}$ elle un picaro, que ben | lle pudo escribir

5 duas le|tras. Buste ten racon en | queigarse del, e mas qua|ndo eu lle mando todos $\mid$ os coreos a mosa donde el | esta a lebar lle as cartas, | pero eu discuro $\mathrm{u}<\mathrm{n}>\mathrm{a} \operatorname{cou} \mid(\mathrm{f}$. $202 v)$ sa: que por ber que eu so $\tan \mid$ faborecida $\mathrm{d}[\mathrm{e}]$ bustede | con una corespondencia 
$\mid$ ta $<\mathrm{n}>$ gustosa de que $<\mathrm{e}>1$ gusta $\mid$ moito e as miñas cartas $\mid$ as ten por suas, pois, aun|que llas mando pedir, | despois que as lea non ai | remedio, ala as enfocha|ca, que para aca non ben | asta que el beña, mais en|tonces a de aber estrei|ta conta.

Sabera bustede, | si non sabe, que Mariño ${ }^{4}$ bai $\mid$ por sargento maior a Mur|cia e o de Murcia aqui | esta a pique que entre $\mid$ o murcio nel, pois aca ca $<\mathrm{n}>\mid$ do entra na carne de le|chon ou na demais chei|ra que penetra. Es una las|(f. 203r)tima el que un cristia|no non se poida purgar $\mid$ ben.

15 Eu funlle, e mais Fa|ruqui[ñ]a, a segar una bei|ga de trigo o Purelo ${ }^{5}$. Bi|ñemos por Santa Marga|rita ${ }^{6}$. Traballamos moi|to. Agora ga podemos ir ala $\mid$ as segas.

As mongas de San|ta Clara ${ }^{7}$ anduberon re|1[ou]cadas de contentas con $\mid$ as suas cartas. A todo o lu|gar as enseñaron. Bustede $\mid$ e un alborotador de cou|sas mui $\mathrm{m}[\mathrm{u}] \mathrm{i}$ benditas.

20 O pa|dre Calderon ${ }^{8}$ estalle mui $\mid$ maliño e dicen que todo $\mid$ e malecolia.

$\mathrm{A}<\mathrm{0}>$ noso gran $\mid$ ilustrisimo padre di|ralle de a nosa parte $\mathrm{u}[\mathrm{n}] \mid$ millon de $\mathrm{c}<0>$ usas de a no|sa boa lei.

A sua sobriña $\mid$ (f. 203v) Faruciña me dice que de $s u<a>$ parte le diga a bustede | que lle quer regale con | un rosario de Jerusalen | mui guapo con sua borla | feita ao

25 uso da corte, pois $\mid$ o que ela ten e mui ordi|nario. Mire que raro mo|do de estafar ten a mi|ña filla. Parece que te|ño de sacar boa disipu|la.

Adios, meu amigiño, | que bou a escribir duas | letriñas a Jabier e son | as nobe da noite de domi|ngo e quero cenar.

Besa La Mano de Vuestra Merced su | mas humilde serbi|dora é faborecida erm $<\mathrm{a}>\mid$ na herMano y Señor fray Martin Maria Madalena | Garcia de Ogando

\footnotetext{
${ }^{2}$ Farruquiña, filla de Magdalena e Xavier e sobriña do bieito pontevedrés afincado no convento madrileño de san Martín, é mencionada varias veces na correspondencia escrita por Sarmiento (1995: 35, 39, 94, 97, 481). Tamén a menciona Magdalena na carta en castelán ao seu cuñado.

${ }^{3}$ Trátase de Francisco Xavier, irmán menor do padre Sarmiento, que naceu en 1700 e desempeñou o cargo de Comisario de Mariña en Pontevedra. É o destinatario máis frecuente das cartas do bieito recompiladas en Sarmiento (1995).

${ }^{4}$ Menciona Sarmiento (1986: 133) un Gonzalo Mariño nun apuntamento de 1754 e tamén un José Mariño nunha anotación de 1745 (Sarmiento 1973: 496) e mais en carta a Xavier do 11 de xullo de 1759 (Sarmiento 1995: 158). A falta de máis datos, non podo identificar a ningún destes dous co Mariño do que aquí fala dona Magdalena.

${ }_{5}^{5}$ O Purrelo é un lugar próximo a Pontevedra que Sarmiento $(1995: 156,182)$ cita non só na súa correspondencia, senón tamén no Catálogo de voces vulgares y en especial de voces gallegas de diferentes vegetables: "Lysimachia purpurea Plinii spicata [...] Vila aun con flor a 17 de septiembre [de 1754] en el arroyo que baja del Purrelo en Val de Corbos" (Sarmiento 1986: 140); “Anónima. [...] Vila y cogila a 17 de septiembre [de 1754] en el arroyo do * Purrelo" (Sarmiento 1986: 142). Valdecorvos é unha entidade situada ao leste do actual núcleo urbano da cidade de Pontevedra (cf. Toponimia de Galicia: http://toponimia.xunta.es/Buscador).

${ }^{6}$ Probablemente a ermida de Santa Margarida de Mourente, situada ao NE de Valdecorvos.

${ }^{7}$ Hai na obra de Sarmiento bastantes referencias ás monxas clarisas de Pontevedra, cuxo convento inspeccionou en 1745 á procura de pergamiños antigos (cf. Rodríguez Montederramo 1998: 458-459).

${ }^{8}$ Trátase probablemente do padre Calderón que Sarmiento lle menciona a Xavier en carta do 22 de marzo de 1747: "Ponme también a la obediencia del Reverendo Padre Maestro Calderón" (Sarmiento 1995: 35).
} 


\subsection{NOTAS DE EDICIÓN}

No encabezamento do folio 202r lese un $<$ U $>$ riscado transversalmente. Trátase dunha marca persoal da remitente que se encontra tamén ao inicio da súa carta en castelán (fol. 200r).

Liñas 2 e 6. Nas dúas ocorrencias da palabra Rodríguez Montederramo edita correos.

Liña 5. Rodríguez Montederramo omite $e$ en "queigarse del, e mas qua|ndo eu" e edita así: "Busté ten racón en queigarse dél, más quando eu lle mando, todos os correos, á mosa donde él está a lebarlle as cartas".

Liña 6. $\mathrm{O}<\mathrm{n}>$ de $u<n>a$ está sobreposto entre $\mathrm{o}<\mathrm{u}>\mathrm{e} \mathrm{o}<\mathrm{a}>$.

Liña 7. Rodríguez Montederramo edita $s o<n>$.

Liña 8. $\mathrm{O}<\mathrm{n}>$ de $t a<n>$ está escrito por riba do $<\mathrm{a}>$; Rodríguez Montederramo edita tan. $\mathrm{O}<\mathrm{e}>$ de $<e>l$ vai escrito sobre $\mathrm{o}<\mathrm{l}>$, e este parece recubrir unha letra subxacente, probablemente $<\mathrm{e}>$; Rodríguez Montederramo edita de que $<e>$ l gusta.

Liña 12. $\mathrm{O}<\mathrm{n}>$ de $c a<n>d o$ está escrito por baixo do $<\mathrm{a}>$. Rodríguez Montederramo edita cando.

Liña 15. No manuscrito, faruquina. Rodríguez Montederramo edita " $E u$ funlle a máis faruquiña a segar...", o que está en contradición co que o mesmo investigador afirmara anteriormente no seu artigo sobre esta pasaxe: "Alude a labores cotidianas como su participación en la siega de una vega de trigo en o "Purelo" junto con su hija Farruquiña" (Rodríguez Montederramo 1998: 459).

Liña 16. Hai un trazo orientado cara á dereita por riba do $<\mathrm{p}>$ inicial de podemos. Inclínome a pensar que é unha simple mancha de tinta sen ningún valor gráfico.

Liña 17. Aínda que hai unha mancha de tinta na segunda sílaba de re|l[ou]cadas, parece lerse, por erro mecánico da remitente, relucadas. Rodríguez Montederramo edita reloucadas.

Liña 21. $\mathrm{O}<_{0}>$ de $A<_{0}>$ está escrito por riba do $<\mathrm{a}>$. Rodríguez Montederramo edita $u$ millón.

Liña 22. $\mathrm{O}<0>$ de $c<0>$ usas está escrito por riba do $<\mathrm{u}>$.

Liña $23 . \mathrm{O}<\mathrm{a}>$ de $s u<a>$ está escrito por baixo do $<\mathrm{u}>$; Rodríguez Montederramo edita sua.
Antes de bustede lese un $<\mathrm{V}>$ non riscado, coma se ao primeiro a remitente pensase escribir Vustede.

Liña 26. Rodríguez Montederramo edita discipula.

Liña 29. No manuscrito hai un trazo levemente ondulado sobre $\mathrm{o}<\mathrm{m}>$ da abreviatura $\mathrm{Vm}$. $\mathrm{O}<\mathrm{a}>$ de erm $<a>n a$ está escrito por riba do $<\mathrm{m}>$; Rodríguez Montederramo edita ermana.

Liña 31. Rodríguez Montederramo edita Magdalena. Madalena é tamén a forma con que a remitente escribiu o seu nome na súa carta en castelán (fol. 201v). No manuscrito en galego os nomes do destinatario e da remitente non están en liñas distintas, como aquí os presento. Dá a impresión de que Magdalena García de Ogando escribiu primeiro o seu nome en dúas liñas da esquina inferior dereita do folio e, despois disto, acordou poñer o do padre Sarmiento á esquerda do dela, pero ao mesmo nivel. Por falta de espazo tivo que desprazar cara abaixo o antropónimo Martín, que aparece levemente inclinado. Por baixo do apelido Ogando trazou unha rúbrica.

\section{COMENTARIO LINGÜÍSTICO}

No magro repertorio de textos en galego dos Séculos Escuros o xénero epistolar ocupa unha discreta posición que, a meu parecer, deberá explicarse máis polo carácter perecedoiro das cartas, a miúdo destruídas polos seus destinatarios, ca por unha presunta particular e pertinaz resistencia a adoptar o idioma do país para a súa redacción. Os altos índices de uso oral do galego nesta época, mesmo entre as persoas instruídas, fanme pensar que durante o XVI, o XVII e o XVIII se escribirían na nosa lingua, total ou parcialmente, en prosa ou en verso, con maior ou menor carga castelanizante, moitas máis cartas das que hoxe coñecemos, que se poden inventariar en moi poucas liñas (cf. Álvarez e Xove 2004a, 2004b, 2013; Álvarez e Rodríguez Montederramo 2004-2005; Mariño Paz 2007; Mariño Paz, Sánchez Yáñez e Suárez Vázquez 2012; Rodríguez Montederramo 1998). Por outra parte, son numerosas as palabras e frases en galego intercaladas en cartas redactadas en castelán durante esta época, así como as cartas escritas nun castelán con maior ou menor interferencia do romance nacido en Galicia. 
A escolla do galego para a comunicación epistolar de Magdalena García de Ogando que aquí edito non vai acompañada de ningunha xustificación, o que invita a pensar que este idioma fluiría espontaneamente entre ela e o padre Sarmiento tamén nas súas comunicacións orais. Desde logo, o tipo de noticias que na carta se comunican evoca unha distendida confianza entre familiares próximos que propiciaría a súa elección por parte de Magdalena. O mesmo tratamento que a remitente lle dispensa ao seu cuñado no inicio da carta ("meu irmanciño") anuncia con toda a propiedade ese ton de sinxela intimidade familiar que a domina de cabo a cabo. Con todo, é evidente que esta espontaneidade tamén se debeu de ver reforzada pola positiva actitude do beneditino ante a única lingua da súa primeira infancia, actitude que alentaría a usala con naturalidade, mesmo por escrito, non só a persoas do seu círculo familiar, senón tamén a amigos como o santanderino padre Rábago, que o 16 de abril de 1754 lle escribiu unha carta que empezaba con algunhas liñas en galego (cf. Rodríguez Montederramo 1998: 460-461). De todos os xeitos, non podemos ignorar que a cuñada de Martín Sarmiento non deixou tampouco de lle pagar o seu tributo ao dominante castelán, ora co cambio de código que nesta cartiña practica para lle poñer énfase ao seu lamento pola falta de aseo persoal dunha persoa ("Es una las|(f. 203r)tima el que un cristia|no non se poida purgar|ben"), ora cos seus castelanismos léxicos e morfolóxicos (Adios, 1. 27; anduberon, 1. 17; asta, 1. 10; aunque, 1. 9; cenar, 1. 28; cristiano, 1. 14; enseñaron, 1. 18; lechon, 1. 13; mas, 1. 5; si, 1. 11; sin, 1. 3), ora na despedida, ora coa adopción desa lingua para a escritura da outra misiva súa que o padre
Sobreira recompilou. Como cabe esperar, nestoutra carta obsérvanse interferencias que operan no outro sentido, é dicir, desde o galego cara ao castelán: "io espero a Jabier el primero o segundo dia del mes que entra en la gran ciudad de Marin a bisitar las carballeiras" (201r); "estafar quatro peigiños i pillar algunas señorias de las pescadeiras, que me pondre mas inchada que Vm. quando iba as mongas" (201v).

Os usos gráficos visibles na carta en galego revelan que dona Magdalena, aínda que certamente recibira instrución, debía de ter trato pouco asiduo coas letras ${ }^{9}$, como por outra parte cabe esperar da súa condición de muller nun tempo e nun lugar en que o analfabetismo e a carencia da educación básica eran a norma entre a inmensa maioría da poboación, e en que a escritura, e particularmente a escritura diaria ou polo menos frecuente, era patrimonio dunha ínfima e selecta minoría entre a que predominaban avultadamente os homes. Para a representación da consoante fricativa prepalatal xorda galega o que se observa na carta é que Magdalena utilizou tamén ante $<\mathrm{a}>\mathrm{o}$ grafema que a ortografía castelá do seu tempo empregaba só ante $<\mathrm{e}>\mathrm{e}$ $<\mathrm{i}>$ para dar conta da fricativa velar xorda, de modo que, a par de sargento (1. 11), escribiu abougar 'abouxar' (1. 2), queigarse 'queixarse' (1. 5), ga 'xa' (1. 16) e mongas 'monxas' (1. $17)^{10}$. Con todo, si sorteou a remitente este uso errado no caso de Jabier (1. 4), ao paso que con Jerusalen (1. 24) tamén atinou coa norma gráfica consagrada; ora ben, dada a súa condición de nomes propios sen tradición autóctona no galego de mediados do XVIII ${ }^{11}$, parece probable que dona Magdalena os pronunciase de forma castelanizante, é dicir, con consoante fricativa velar xorda ou con outra articulación

\footnotetext{
${ }^{9}$ Coido que cómpre interpretar da mesma maneira as deficiencias observadas na epígrafe 2 a propósito da puntuación e da partición do texto en parágrafos. Discreto ou indirecto contacto coa lectura, mais non enteira familiaridade con ela, creo que é o que transparenta a forma con que dona Magdalena adoptou o cultismo melancolía: malecolia (1. 20).

${ }^{10} \mathrm{Na}$ carta en castelán escribiu $<\mathrm{j}>$ por $<\mathrm{g}>$ en dijanlo (201r) e $<\mathrm{g}>$ por $<\mathrm{j}>$ en mongas (201v).

${ }^{11}$ Como nome de persoa masculino, Jabier, de orixe navarra, só puido empezar a expandirse a partir da existencia de san Francisco Xavier (1506-1552), pero tardaría en gañar certa popularidade en Galicia. Jerusalen era evidentemente un exónimo, isto é, o nome dunha cidade non galega que, debido á súa relevancia, probablemente se daba a coñecer a moitos galegos a través do filtro do castelán, e sobre todo pola prédica e o adoutrinamento relixiosos.
} 
consonántica similar a esta. Deficiente dominio dos bos usos gráficos do seu tempo ${ }^{12}$ revelan igualmente o emprego exclusivo de $<\mathrm{b}>$ para /b/ (escribin, 1. 2; abougar, 1. 2; lebar, 1. 6; ber, 1. 7; bustede, 1s. 7, 11, 23 $3^{13}$; nobe, 1. 27; etc.), a omisión de $<\mathrm{h}>$ no castelán erma $<n>a$ (1. 29), o uso constante de $<\mathrm{r}>$ en posición intervocálica interior de palabra para representar a vibrante múltiple (coreos, 1s. 2, 6; Faruquiña, 1. 4; dis-

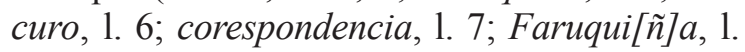
15; Purelo, 1. 15; Faruciña, 1. 23), o de $<\mathrm{c}>+$ $<\mathrm{i}>$ para /k/ (Faruciña, 1. 23), o de $<\mathrm{g}>$ (e non $<\mathrm{gu}>$ ) ante $<\mathrm{i}>$ para /g/ (amigiño, 1. 27) $)^{14}$, o de $<\mathrm{c}>+<_{0}>$ para a fricativa predorsal, apical ou interdental xorda (racon 'razón', 1. 5) ${ }^{15}$ e certas particións de palabras ao final de liña ( $m a \mid i s, 1$. 4; Jabi|er, 1. 4; qua|ndo, 1. 5; domi|ngo, 1. 28). Á vista de todo o anterior, non pode estrañar a falta de <-ss-> no superlativo ilustrisimo (1. 21) (e menos aínda nos posesivos noso e nosa, 1s. 21 e 22, inexistentes na lingua dominante), xa que a distinción entre $<-$ s- $>$ e $<$-ss- $>$, tanto en galego como en castelán, era a mediados do século XVIII un uso declinante só dominado xa polos moi instruídos, ata o punto de que a Real Academia Española renunciou definitivamente a el no seu tratado ortográfico de 1763 . No nivel gráfico cómpre subliñar ademais que a escolla de $<$ n $>$ para representar a consoante nasal velar galega se inspiraría nas formas una, alguna, etc. do castelán que dona Magdalena recibiría coa aprendizaxe das primeiras letras: $u<n>a$ (1. 6), una $(1 \mathrm{~s} .7,15)$.

En dúas palabras (mosa, 1. 6, e disipula, 1. 26) aflora explicitamente un seseo prenuclear que, por máis que na época estivese máis estendido cara ao leste ca na actualidade (cf. Mariño Paz 1996: 85-86), foi probablemente tomado pola remitente da Pontevedra onde se estableceu, e non do Viveiro en que se criou ${ }^{16}$. Inclíname a favor desta interpretación a selección doutras catro variantes inequivocamente pontevedresas que, polo contrario, non debían de usarse daquela en Viveiro, como inducen a pensar os datos da dialectoloxía galega actual: irmanciño (1. 1) e non irmauciño, os adverbios de lugar aca (ls. $10,12)$ e ala $(1 \mathrm{~s} .9,16)$ e non acó nin aló, podo (1. 3) en lugar de poido e pudo (1. 4) en vez de puido. Outros usos non me parecen definitorios a este respecto, xa que creo que a mediados do XVIII se debían de dar tanto na Boa Vila coma en Viveiro: moito(s) (1s. 2, 8, 16), que alterna no texto coa variante apocopada mui (1s. 18, 20, $24,25)^{17} ; c a<n>d o$ (1. 12), que así e todo comparte espazo con quando (1. 5); escribin (1. 2) no canto de escribi; e poida (1. 14) en vez de poda. Finalmente, non vexo na carta variantes adscribibles a Viveiro que probablemente non fosen tamén propias da Pontevedra de arredor de 1755.

Do punto de vista da historia da lingua galega demandan tamén comentario, por lacónico que sexa, os seguintes aspectos:

1. Os grupos consonánticos heterosilábicos simplifícanse de acordo coas pautas evolutivas propias das palabras patrimoniais: disipula (1. 26), Madalena (1.31).

2. Do dativo de solidariedade, rexistrado con certeza desde finais do XVI (cf. Mariño Paz 2003: 138), faise na carta un uso frecuente que cadra perfectamente co ton coloquial que a domina: "Jabier elle un picaro" (1. 4), "Eu funlle [...] a segar una beiga de trigo" (1. 15), "O padre Calderon estalle mui maliño" (1. 20).

3. O tratamento de buste (1. 5) ou bustede (ls. $7,11,18,23)$ que Magdalena lle dispensa nesta

12 Sobre os usos gráficos dominantes no castelán daquel tempo (a lingua en que os galegos alfabetizados habitualmente escribían) e as prescricións que ao respecto foi acordando a Real Academia Española cf. Real Academia Española (1726-1739: I, LXI-LXXXIV; 1741).

${ }^{13}$ Téñase presente que a posibilidade de que na liña 23 dona Magdalena valorase a posibilidade de escribir Vostede non é máis ca unha conxectura.

${ }^{14} \mathrm{Na}$ carta en castelán lémoslle encarge 'encargué' (200r).

${ }^{15} \mathrm{Na}$ carta en castelán escribiu Morraco 'Morrazo' (200r).

${ }^{16} \mathrm{O}$ seseo pontevedrés tamén aflora na carta en castelán: dies 'diez' (200r).

${ }^{17}$ Moito debía de utilizarse xa na vila do Lérez, por máis que en terras próximas a ela se estilase o muito. 
carta ao seu cuñado, e non o máis informal de $v{ }^{18}{ }^{18}$, é o esperable a mediados do XVIII para se dirixir a unha persoa que, aínda compartindo coa muller que llo aplica a máis estrita intimidade familiar, ocupa respecto dela unha posición de superioridade debida tanto á súa maior idade como á súa condición de relixioso e de sobranceiro intelectual da corte borbónica do seu tempo.

4. No ámbito da morfoloxía verbal cómpre subliñar a selección das variantes conservadoras no caso de tres variables que a mediados do século XVIII estaban inmersas en procesos de cambio de longo percorrido no devir diacrónico da lingua galega: (eu) so (1. 7) e non (eu) son, ben (1.10) no canto de veñen e, finalmente, dice (1. 23) e dicen (1. 20) en lugar de di e din. Así mesmo, en vez de quere seleccionou quer (1. 24), a variante dominante no galego medieval para a expresión da $\mathrm{P} 3$ do presente de indicativo de querer.

5. O rexistro coloquial da carta en que se utiliza pon en evidencia que a perífrase verbal ter de + infinitivo ("Parece que teño de sacar boa disipula", 1.26) tiña a mediados do século XVIII un uso no galego oral do que carece na actualidade. Este noso dato está en liña co feito de que esta perífrase gozase dunha "presenza frecuente en textos decimonónicos de extracción popular, inclusive nos que denotan a hibridación lingüística" (Freixeiro Mato, Sánchez Rei e Sanmartín Rei 2005: 536). Cómpre subliñar que nesta carta de dona Magdalena García de Ogando a perífrase ten un valor claramente prospectivo, non obrigativo.

6. No terreo do léxico farei só brevísimas anotacións. Que eu saiba, a deste texto é a primeira documentación do substantivo murcio (1. 12) nas fontes galegas, xa que a máis antiga que ofrece a ferramenta RILG é só a do vocabulario de Bernardo Vicente Payzal (1800), que o define como "olfato malo de las carnes; husmo". Consonte os datos subministrados tamén por RILG, o rexistro do verbo estafar (1. 25) que lemos nesta carta é igualmente o máis antigo nas fontes galegas coñecidas, posto que o primeiro que alí se dá data só de 1859 , se ben o substantivo estafas xa aparece na Felicitación critica por dos labradores gallegos (1842) de Vicente Turnes. Outros rexistros léxicos desta cartiña dignos de mención pola súa antigüidade son abougar 'abouxar' (1. 2), corespondencia (1. 7) na acepción de 'relación epistolar', disipula ${ }^{19}$ (1. 26) e picaro (1. 4). O RILG non subministra ningún rexistro do verbo enfochacar 'gardar' (cf. 1. 9).

Creo, en definitiva, que esta carta de Magdalena García de Ogando ao padre Sarmiento, a pesar da súa brevidade, constitúe unha preciosa fonte de información para o investigador que queira achegarse á historia externa e interna do galego medio e, particularmente, á historia do galego no século XVIII.

\section{REFERENCIAS BIBLIOGRÁFICAS}

Álvarez, Rosario e Rodríguez Montederramo, Xosé Luís (2004-2005): “Escrita epistolar en galego: a correspondencia de Don Diego Sarmiento de Acuña, I Conde de Gondomar (15671626) (I)", Boletín da Real Academia Galega 365, pp. 253-291; e (II), Boletín da Real Academia Galega 366, pp. 225-303.

Álvarez, Rosario e Xove, Xosé (2004a): “Un testamento do galo de 1786”, en T. Amado Rodríguez et alii (eds.), Iucundi acti labores. Estudios en homenaje a Dulce Estefanía Álvarez. Santiago de Compostela: Universidade, pp. 501-525.

\footnotetext{
${ }^{18}$ Sobre o uso destes pronomes de respecto no século XVIII e na primeira metade do XIX cf. Mariño Paz (2003: 107-108, 127-135).

${ }^{19}$ Para este cultismo o RILG ofrece un primeiro rexistro de 1835, mais xa se le condicipalo no verso 395 do romance da urca de Santo Antón, de 1777 (cf. Mariño Paz, Sánchez Yáñez e Suárez Vázquez 2012).
} 
(2004b): “Achegas para a historia da lingua: unha carta do século XVIII”, en R. Álvarez e A. Santamarina (eds.), (Dis)cursos da escrita: estudos de filoloxía galega ofrecidos en memoria de Fernando R. Tato Plaza. A Coruña: Fundación Pedro Barrié de la Maza, pp. 35-64.

(2013): "Cartas que cruzan o Miño. Correspondencia con don Pedro Álvarez V de Soutomaior, falsificador (1527)", en R. Álvarez et alii (eds.), Ao sabor do texto. Estudos dedicados a Ivo Castro. Santiago de Compostela: Instituto da Lingua Galega / Universidade, pp. 29-55.

Freixeiro Mato, Xosé Ramón, Sánchez Rei, Xosé Manuel e Sanmartín Rei, Goretti (2005): $A$ lingua literaria galega no século XIX. A Coruña: Universidade.

MARIÑo PAZ, Ramón (1996): “Aproximación ó mapa dialectal galego dos séculos XVIII e XIX”, en R. Lorenzo e R. Álvarez (eds.), Homenaxe á profesora Pilar Vázquez Cuesta. Santiago de Compostela: Universidade, pp. 77-105.

(2003): O idioma galego no limiar da súa renacenza. Estudo lingüístico de textos pregaleguistas. Monografía 2 da Revista Galega de Filoloxía. A Coruña: Universidade.

(2007): "Edición e estudo lingüístico do romance de María Francisca de Isla y Losada ao cura de Fruíme (ca. 1774-1777)”, Revista Galega de Filoloxía 8, pp. 57-98.

Mariño PAZ, Ramón, SÁnchez Yáñez, Margarita, SuÁrez VÁzQuez, Damián (2012): O romance da urca de Santo Antón. Poesía en galego no Ferrol do século XVIII. A Coruña: Fundación Barrié.

Real Academia Española (1726-1739): Diccionario de la lengua castellana. 6 vols.: vol. 1: Madrid: Francisco del Hierro, 1726; vol. 2: Madrid: Francisco del Hierro, 1729; vol. 3: Madrid: Viuda de Francisco del Hierro, 1732; vol. 4: Madrid: Herederos de Francisco del Hierro, 1734; vol. 5: Madrid: Herederos de Francisco del Hierro, 1737; vol. 6: Madrid: Herederos de Francisco del Hierro, 1739. Ed. facsímil: Diccionario de Autoridades. Madrid: Gredos, 3 vols., 1990.

(1741): Orthografia Española. Madrid: En la Imprenta de la Real Academia Española.

RILG: Recursos Integrados da Lingua Galega (RILG): http://sli.uvigo.es/RILG/ [decembro 2013 xaneiro 2014].

Rodríguez Montederramo, José Luis (1998): "Una carta en gallego dirigida al P. Sarmiento: Nota sobre la actitud lingüística del benedictino", en N. Delbecque e C. de Paepe (eds.), Estudios en honor del profesor Josse de Kock. Leuven: Leuven University Press, pp. 457-467.

SARMIENTO, Fray Martín (1973): Catálogo de voces y frases de la lengua gallega (Edición y estudio por J. L. Pensado). Salamanca: Universidad.

(1986): Catálogo de voces vulgares y en especial de voces gallegas de diferentes vegetables. (Edición y estudio por J. L. Pensado). Salamanca: Universidad.

(1995): Epistolario (Disposto por Xosé Filgueira Valverde e $M^{a}$ Xesús Fortes Alén). Santiago de Compostela: Consello da Cultura Galega. 


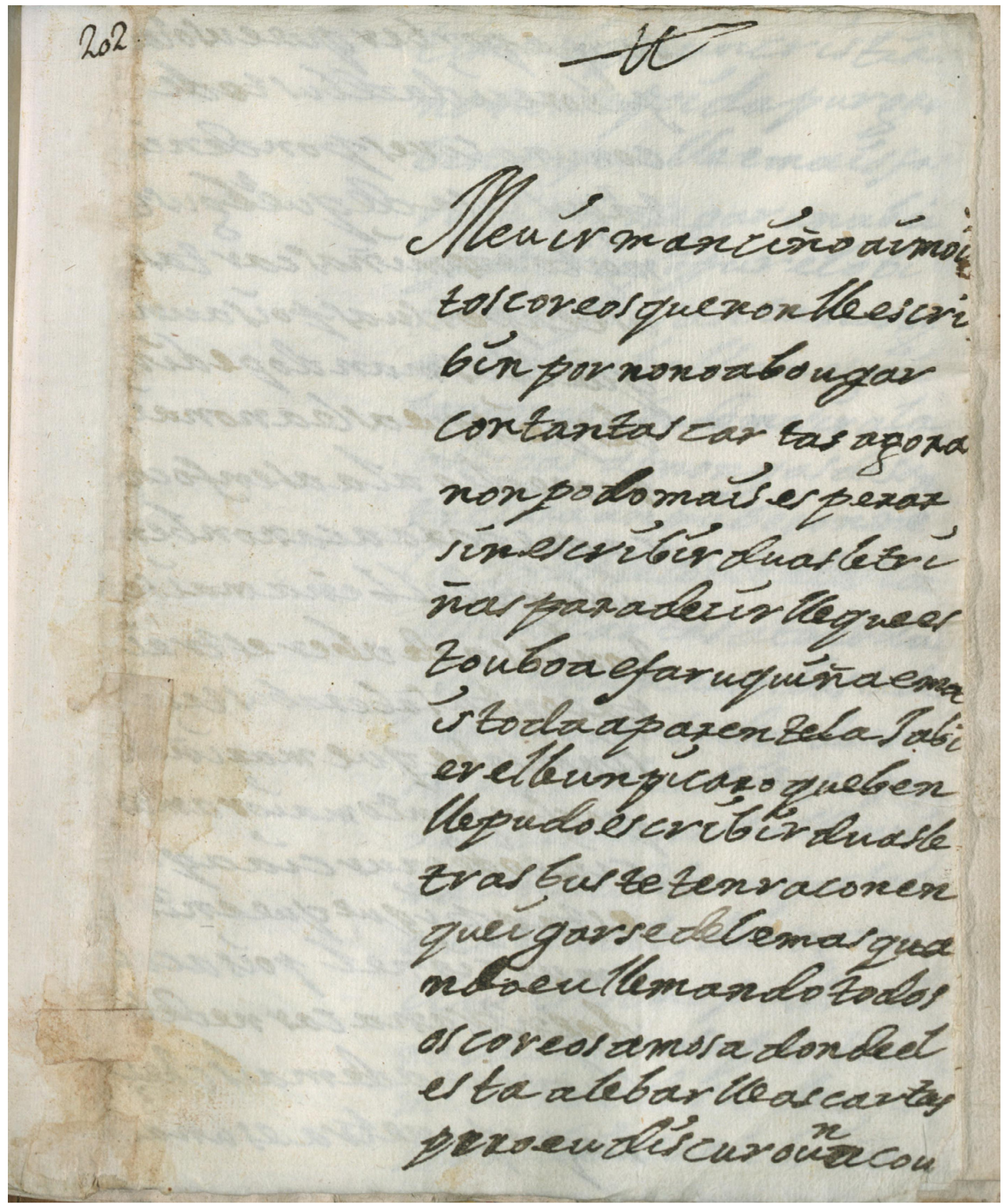

Ms. 9-5761 da RAH (fol. 202r) 


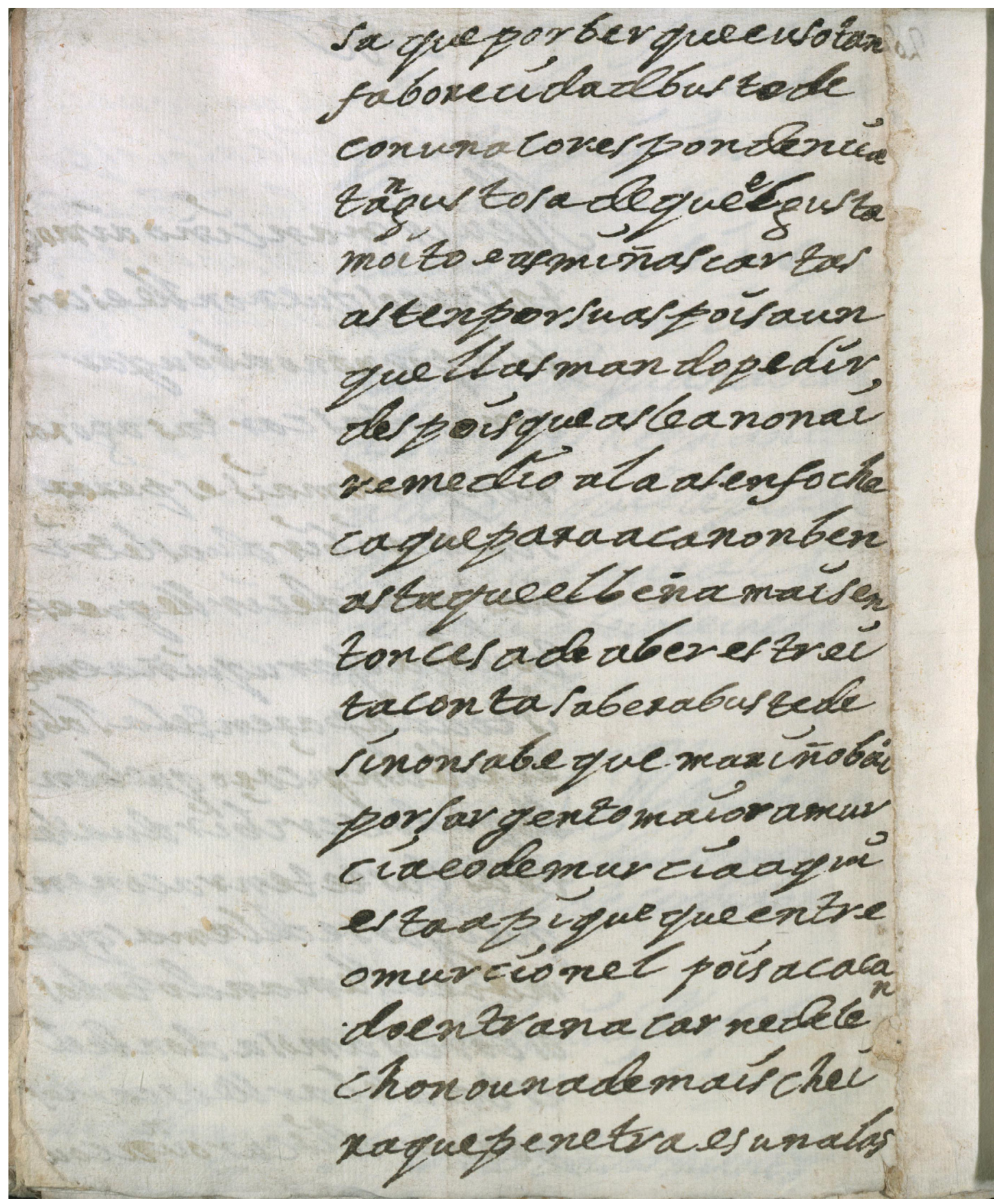

Ms. 9-5761 da RAH (fol. 202v) 
203

Eimaetofueuricoista nonon epoidapureas ben eufuntle emaisfax vugina aregar unabei zadezrigo of puretobi ñemol por anzamarg * ctectraballanesmo. toagorad ápodemoscrata arsegas dinongallerasia zactaraandubexune. lacourdecontentafor. assualcartas atalodu" gurapenteñazorbusteder Seunatboxotador decon. lasmmibendica opa, drecatdoxonerzatlemú. matiñodicenquetado enatecoliá dirsos oran Utuptrisimo padredi. xalledenolaparzen metlondecin at deano: saboateciasuatobriña

Ms. 9-5761 da RAH (fol. 203r) 


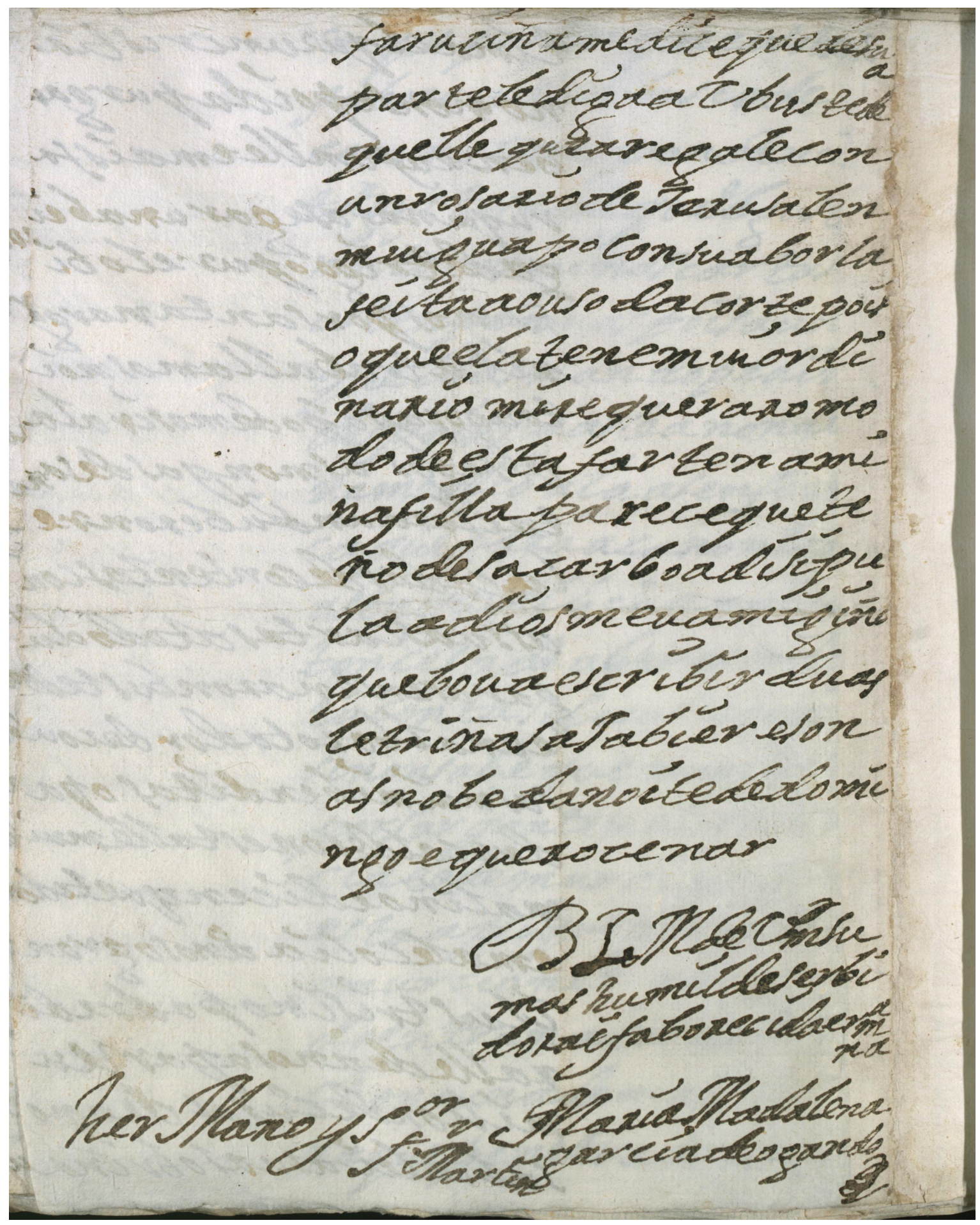

Ms. 9-5761 da RAH (fol. 203v) 